\title{
DIOXINS IN BILE IN RELATION TO THOSE IN THE HUMAN LIVER AND BLOOD
}

\author{
Kimiyoshi KITAMURA ${ }^{1, *}$, Minako NAGAO ${ }^{1}$, Taketo YAMADA ${ }^{2}$, \\ Masahiro SUNAGA ${ }^{3}$, Jun-ichi HATA ${ }^{2}$ and Shaw WATANABE ${ }^{3}$ \\ ${ }^{1}$ Laboratory of Protection of Body Function, Faculty of Applied Bioscience, Tokyo University of Agriculture \\ 1-1-1 Sakuragaoka, Setagayaku, Tokyo 156-8502 \\ ${ }^{2}$ Department of Pathology, School of Medicine, Keio University, \\ 35 Shinanomachi, Shinjuku, Tokyo 160-8582 \\ ${ }^{3}$ Laboratory of Public Health Nutrition and Epidemiology, Faculty of Applied Bioscience, Tokyo University of Agriculture, \\ 1-1-1 Sakuragaoka, Setagaya, Tokyo 156-8502, Japan
}

(Received May 14, 2001; Accepted September 26, 2001)

\begin{abstract}
The levels of 20 dioxin congeners, 7 polychlorinated dibenzo- $p$-dioxins (PCDDs), 10 polychlorinated dibenzofurans (PCDFs) and three coplanar polychlorinated biphenyls (Co-PCBs), in bile were examined in comparison with those in the blood and liver, in 27 autopsy cases. Total-TEQ values

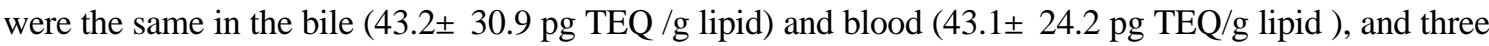
times higher in the liver (127.8 $57.4 \mathrm{pg}$ TEQ/g lipid). Highly chlorinated PCDDs and PCDFs have a tendency to accumulate in the liver, and their levels in bile and blood were relatively low compared with those in the liver, with 1,2,3,4,6,7,8-heptachlorodibenzofuran having the highest tendency among the 20 congeners. Daily excretion in bile was calculated to be $54 \mathrm{pg}$ TEQ at age 65 , by assuming that daily bile secretion is $750 \mathrm{ml}$ and is concentrated 7.5-fold in the gallbladder. The correlation between bile and blood total-TEQ was high, with a correlation coefficient of 0.89 among the 27 autopsy cases. Thus, the regression equation of $\mathrm{y}=1.14 \mathrm{x}-6.02$ will provide us levels in bile (total TEQ per g lipid), knowing the blood total-TEQ level, where $\mathrm{x}$ is total-TEQ per $\mathrm{g}$ lipid of the blood. Furthermore, accumulation of dioxins was estimated to be $0.99,0.70$ and $1.91 \mathrm{pg}$ TEQ/g lipid /year in bile, blood and liver, respectively.
\end{abstract}

KEY WORDS: PCDD, PCDF, Co-PCB, Bile, Blood, Liver

\section{INTRODUCTION}

At present in our environment, dioxins, including polychlorinated dibenzo- $p$-dioxins (PCDDs), polychlorinated dibenzofurans (PCDFs) and coplanar polychlorinated biphenyls (Co-PCBs), are mainly produced by heating waste in incinerators, and are then emitted in the exhaust gas and fly ash. Dioxins are chemically stable, lipophilic compounds, and they accumulate in fish, meat and dairy products (Schecter et al., 1996; Toyoda et al., 1999). Humans are exposed to dioxins mainly through food in daily life, and data of human exposure to dioxins based on blood levels are accumulating (International Agency for Research on Cancer, 1997; US Department of Health and Human Services, 1998).
However, studies of the distribution of dioxins in the human body and excretion from the body are very limited. We have recently clarified that gastrointestinal absorption of dioxins is not directly associated with the number of chlorine atoms of the congeners, and each compound has its own characteristic features of metabolism (Kitamura et al., 2001). 1,2,3,7,8,9-hexachlorodibenzofuran (1,2,3,7,8,9-HxCDF), 1,2,3,7,8pentachlorodibenzofuran (1,2,3,7,8-PeCDF), 1,2,3, 4,7,8,9-heptachlorodibenzofuran $(1,2,3,4,7,8,9$ HpCDF), 2,3,7,8-tetrachlorodibenzofuran (2,3,7,8TCDF), octachlorodibenzo- $p$-dioxin (OCDD) and 1,2,3,4,7,8-hexachlorodibenzo- $p$-dioxin $(1,2,3,4,7,8$ HxCDD) were well absorbed from the gastrointestinal tract after ingestion, and OCDD, 2,3,7,8-TCDF and

* Present address: National Institute for Environmental Studies, 16-2 Onogawa, Tsukuba, Ibaraki 305-0053, Japan 


\section{K. KITAMURA et al.}

3,3'4,4'-tetrachlorobiphenyl (3,3'4,4'-TCB) were efficiently excreted from sebum but 1,2,3,4,7,8-HxCDD was scarcely excreted. In total-TEQ, about $22 \%$ of the ingested dioxins were excreted from feces and 29\% from sebum, while the fate of the other $50 \%$ is not clear at present (Kitamura et al., 2001). Since the half-life of 2,3,7,8-tetrachlorodibenzo- $p$-dioxin (2,3,7,8-TCDD) in humans has been estimated to be 5.8 9.5 years (Michalek et al., 1996; Ott and Zober, 1996), and 33 years for 2,3,4,7,8-PeCDF (Rohde et al., 1999), these dioxins might be subjected to enterohepatic circulation. Thus, prevention of absorption of dioxins from the intestines would be helpful for reduction of body burden of dioxins after accidental exposure. For this purpose, we first need to clarify levels of dioxins in bile. In this study, we clarified dioxin levels of seven major PCDDs, 10 PCDFs and three coplanar PCBs in the bile of 27 autopsy patients, in relation to blood levels, for estimation of dioxin in bile from blood levels.

\section{MATERIALS AND METHODS}

\section{Chemicals}

Authentic PCDDs, PCDFs and Co-PCBs, and ${ }^{13} \mathrm{C}_{12}$-PCDDs, ${ }^{13} \mathrm{C}_{12}$-PCDFs and ${ }^{13} \mathrm{C}_{12}$-Co-PCBs were purchased from Wellington Laboratories (Ontario, Canada). All solvents used were of dioxin-analysis grade (Kanto Chemicals, Tokyo, Japan).

\section{Sample preparation}

Gallbladder bile, cardiac blood and liver tissue were obtained from 27 cadavers at autopsy with the permission of the bereaved families, and were stored at $-80^{\circ} \mathrm{C}$ until use. About $50 \mathrm{~g}$ of bile, more than $50 \mathrm{~g}$ of blood and about $5 \mathrm{~g}$ of liver tissue were stored from each cadaver. The ages and diagnoses of dead subjects are summarized in Table 1.

\section{Preparation of samples for dioxin analysis 1. Bile}

Forty g of bile was transferred to a $250 \mathrm{ml}$ centrifuge-tube, $30 \mathrm{pg}$ of ${ }^{13} \mathrm{C}_{12}-\mathrm{TCDD} / \mathrm{F} \sim \mathrm{HpCDD} / \mathrm{F}, 60$ pg of ${ }^{13} \mathrm{C}_{12}-\mathrm{OCDD}, 100 \mathrm{pg}$ of ${ }^{13} \mathrm{C}_{12}-\mathrm{TCB} \sim \mathrm{HxCB}$ were added, and then a lipid fraction containing dioxins was obtained by extracting with $160 \mathrm{ml}$ of acetone $/ n$-hexane (2:1), and then $n$-hexane three times. The extracts were washed with ultra-pure water and the hexane fractions were pooled and dried by passing through a column containing $10 \mathrm{~g} \mathrm{Na}_{2} \mathrm{SO}_{4}$, concentrated to about $1 \mathrm{ml}$ by a rotary evaporator, and then spontaneously dried by standing at room temperature. The lipid fraction was then weighed. The lipid fraction was dissolved in $50 \mathrm{ml}$ $n$-hexane, and treated with $20 \mathrm{ml} \mathrm{concH}_{2} \mathrm{SO}_{4}$ to remove a large amount of lipid.

\section{Blood}

Fifty g of blood was transferred to a $250 \mathrm{ml}$ centrifuge-tube, and to this ${ }^{13} \mathrm{C}_{12}$-isomers were added as described above, and then dioxin extraction was performed within the same day. A lipid fraction that contained dioxins was extracted by the $\left(\mathrm{NH}_{4}\right)_{2} \mathrm{SO}_{4}$ ethanol/hexane method (Miyata et al., 1998).

\section{Liver}

The method reported by Iida et al. (1999) was applied with a minor modification. Briefly, $1.5 \mathrm{~g}$ of liver tissue was homogenized in a mortar in the presence of the same amount of $\mathrm{Na}_{2} \mathrm{SO}_{4}$ (Beck et al., 1990) and transferred to a $100 \mathrm{ml}$ tube. Then, ${ }^{13} \mathrm{C}_{12}$-isomers were added. A lipid fraction was obtained by extracting with $50 \mathrm{ml}$ acetone $/ n$-hexane $(2: 1)$, and then $n$-hexane three times.

\section{Clean-up}

The lipid fraction and the $n$-hexane fraction treated with $\mathrm{H}_{2} \mathrm{SO}_{4}$ were dissolved in 2-3 $\mathrm{ml} n$-hexane and subjected to a clean-up process. Clean-up was achieved by passing the fraction through a multi-layer column composed of $\mathrm{Na}_{2} \mathrm{SO}_{4}$, silica gel, 10\% (w/w) $\mathrm{AgNO}_{3}-$ silica gel, silica gel, 22\% (w/w) $\mathrm{H}_{2} \mathrm{SO}_{4}$-silica gel, silica gel, 44\% (w/w) $\mathrm{H}_{2} \mathrm{SO}_{4}$-silica gel, silica gel, $2 \%(\mathrm{w} / \mathrm{w})$ $\mathrm{KOH}-$ silica gel and silica gel (Miyata et al., 1989). After elution with $150 \mathrm{ml}$ of $n$-hexane the specimen was evaporated to a small volume. The concentrate was applied to an active carbon-impregnated silica gel column (Masuzaki et al., 1999), washed with $200 \mathrm{ml}$ of $25 \%(\mathrm{v} / \mathrm{v})$ dichloromethane/ $n$-hexane, and then eluted with $200 \mathrm{ml}$ of toluene. Five $\mu 1$ of $n$-nonane containing ${ }^{13} \mathrm{C}_{12}-1,2,3,4-\mathrm{TCDD}$ and ${ }^{13} \mathrm{C}_{12}-1,2,3,7,8,9-\mathrm{HxCDD}$ spiking substances was added to this vessel (Safe, 1991). Samples dissolved in $n$-nonane were subjected to GC/MS.

\section{GC/MS}

PCDDs, PCDFs and Co-PCBs were analyzed by GC-MS, according to the method used by the Environmental Protection Agency, U.S. (EPA, USA, Office of Water, 1994). The analytical conditions were as follows: gas chromatography was performed with an HP 6890 series unit (Hewlett-Packard, Palo Alto, CA) equipped with a Finnigan MAT-95S (Finnigan MAT $\mathrm{GmbH}$, Bremen, Germany). The column used was a 
Dioxins in bile of humans.

DB5MS fused silica capillary column, $0.25 \mathrm{~mm}$ i.d. $\times$ $60 \mathrm{~m}$, with $0.25 \mu \mathrm{m}$ film thickness (J\&W Scientific, Folsom, CA). The column temperature was maintained at $140^{\circ} \mathrm{C}$ for $1 \mathrm{~min}$, heated to $220^{\circ} \mathrm{C}$ at a rate of $17^{\circ} \mathrm{C}$ / min, heated to $310^{\circ} \mathrm{C}$ at a rate of $3^{\circ} \mathrm{C} / \mathrm{min}$, and maintained at $310^{\circ} \mathrm{C}$ for $4 \mathrm{~min}$. The injection temperature was $260^{\circ} \mathrm{C}$, ion source temperature was maintained at $250^{\circ} \mathrm{C}$ and the carrier gas (helium) flow rate was 1.2 $\mathrm{ml} / \mathrm{min}$. The ionizing current, ionizing energy and accelerating voltage were $1 \mathrm{~mA}, 60 \mathrm{eV}$ and $5 \mathrm{kV}$, respectively. The resolution of the mass spectrometer was maintained at about 10,000 throughout the work, and the analysis was carried out according to a selected ion monitoring (SIM) using 50 selected ions, $\mathrm{M}^{+}$and $\mathrm{M}^{+2}$ for TCDD, TCDF and TCB, and $\mathrm{M}^{+2}$ and $\mathrm{M}^{+4}$ for other congeners. The ${ }^{13} \mathrm{C}$ standard of OCDF was not available. Deviations of the ion intensity ratio values of samples were less than $15 \%$ of the theoretical values.

A standard curve for quantification of each chemical was obtained using authentic congeners. Recovery of all congeners was more than $50 \%$. Vehicle controls were lower than the detection limits for all dioxins examined in this study.

\section{Statistical analysis}

SPSS version 10.0J (1999) was used for the statistical snalyses.

\section{RESULTS}

\section{Levels of dioxins in the bile, blood and liver}

Dioxin levels in amount and TEQ in the bile, blood and liver are summarized in Table 2. OCDD is the most abundant among 20 congeners in these organs, followed by three Co-PCBs on a pg /g lipid basis.

The total pg TEQ values per $\mathrm{g}$ lipid were almost the same in bile and blood at $43.2 \pm 30.9$ and $43.1 \pm$ 24.2 , respectively (Table 2 ). On the other hand, it is three times higher in the liver, being $127.8 \pm 57.4 \mathrm{pg}$ TEQ. The lipid weights in bile, blood and liver were $1.24 \pm 0.75,0.4 \pm 0.04$ and $5.09 \pm 2.50 \%$, respectively, and total TEQ per unit tissue-weight was 3 times higher in bile than in blood, 38 times higher in liver than in blood, and 12 times higher in liver than in bile. Table 2 also shows the TEQ values of the congener groups. The contribution of each group to the total-TEQ was the same in blood and bile; however, the contribution of PCDDs was relatively small, and that of PCDFs was relatively large in the liver (PCDDs, 36\%; PCDFs, $34 \%$ ) compared with the bile and blood (PCDDs, 42\%; PCDFs, 27\%). Among 20 congeners, the contribution of 3,3'4,4'5-pentachlorobiphenyl (3,3'4,4'5-PeCB), 2,3,4,7,8-PeCDF and 1,2,3,7,8-pentachlorodibenzo- $p$ dioxin $(1,2,3,7,8-\mathrm{PeCDD})$ were the most, accounting for more than $70 \%$ of the total-TEQ in all these three organs. 1,2,3,6,7,8-HxCDD and 2,3,7,8-TCDD fol-

Table 1. Diagnoses at death.

\begin{tabular}{|c|c|c|c|}
\hline \multicolumn{2}{|r|}{ Female } & \multicolumn{2}{|r|}{ Male } \\
\hline Age & Disease & Age & Disease \\
\hline 29 & Acute myelocytic leukemia & 21 & Cerebral palsy \\
\hline 33 & Spinal cord tumor & 50 & Brain tumor \\
\hline 53 & Polyarteritis & 52 & Dissecting aneurysm \\
\hline 58 & Pancreatic carcinoma & 63 & Acute cardiac infarction \\
\hline 73 & Rheumatoid arthritis & 63 & Lung cancer \\
\hline 74 & Malignant lymphoma, Diabetes mellitus & 65 & Pulmonary fibrosis \\
\hline 75 & Thalamic hemorrhage & 66 & Pancreatic carcinoma \\
\hline 76 & Acute myelocytic leukemia & 67 & Hepatoma, Gastric cancer \\
\hline 77 & Urinary bladder cancer & 68 & Primary biliary cirrhosis \\
\hline 83 & Cor pulmonale & 68 & Urothelial cancer \\
\hline 84 & Urothelial cancer & 68 & Malignant lymphoma, Colon cancer \\
\hline \multirow[t]{4}{*}{85} & Ovarian cancer & 68 & Prostate cancer \\
\hline & & 73 & Lung cancer \\
\hline & & 77 & Hepatoma, Malignant lymphoma \\
\hline & & 77 & Lung cancer \\
\hline
\end{tabular}




\section{K. KITAMURA et al.}

lowed and accounted for more than $10 \%$ of the total TEQ in the three organs.

The characteristics of organ distribution of each compound were examined (Table 3). Ratios of the values per g lipid in the bile to the blood were between 0.5 and 1.5, indicating that distribution in these body fluids of each compound was almost the same, except for OCDF, which was one-tenth the value in bile of that in blood. It was also revealed that highly chlorinated congeners of PCDDs and PCDFs were lower in bile than in blood, although the levels of all three PCB congeners were almost the same in the bile and blood.

The ratio of the amount in the liver to the blood on a $g$ lipid basis revealed that $1,2,3,4,6,7,8-\mathrm{HpCDF}$ has the highest tendency to accumulate in the liver; distribution to the blood was low, and to the bile was lower. The other highly chlorinated congeners of PCDDs and PCDFs showed a similar tendency, although the extent was lower in the other congeners. Among the three Co-
PCBs, the tendency was opposite to the number of chlorine atoms, and the ratio of the liver TEQ to the bile TEQ was the highest with $3,3^{\prime} 4,4^{\prime}$-TCB on a $\mathrm{g}$ lipid basis.

\section{Daily secretion of dioxins into the bile}

Daily secretion of bile from the liver is known to be about $500 \sim 1000 \mathrm{ml}$, and it is concentrated 5 10fold in the gallbladder. Thus, the daily amount of gallbladder bile can be calculated as $100 \mathrm{ml}$, assuming that the daily bile secreted from the liver is $750 \mathrm{ml}$ and concentrated 7.5-fold. Based on this value, the daily secretion into bile of the total-TEQ, and of each congener group is indicated in Table 4. Daily secretion was calculated to be $53.9 \pm 52.5 \mathrm{pg}$ TEQ at age 65 , from an average of the 27 cases.

\section{Relationship among bile, blood and liver TEQ}

Correlation between blood TEQ and bile TEQ is

Table 2. PCDD / PCDF / Co-PCB levels in bile, blood and liver.

\begin{tabular}{|c|c|c|c|c|c|c|c|c|c|c|c|c|}
\hline \multirow[b]{3}{*}{ 2,3,7,8-TCDD } & \multicolumn{6}{|c|}{ Mean \pm SD (pg / g lipid) } & \multicolumn{6}{|c|}{ Meant SD (pg TEQ / g lipid) } \\
\hline & \multicolumn{2}{|c|}{ Bile } & \multicolumn{2}{|c|}{ Blood } & \multicolumn{2}{|c|}{ Liver } & \multicolumn{2}{|c|}{ Bile } & \multicolumn{2}{|c|}{ Blood } & \multicolumn{2}{|c|}{ Liver } \\
\hline & $3.6 \pm$ & 3.5 & $2.6 \pm$ & 2.0 & $8.0 \pm$ & 6.5 & $3.6 \pm$ & 3.5 & $2.6 \pm$ & 2.0 & $8.0 \pm$ & 6.5 \\
\hline 1,2,3,7,8-PeCDD & $10.5 \pm$ & 8.3 & $9.9 \pm$ & 6.4 & $24.4 \pm$ & 16.8 & $10.5 \pm$ & 8.3 & $9.9 \pm$ & 6.4 & $24.4 \pm$ & 16.8 \\
\hline $1,2,3,4,7,8-\mathrm{HxCDD}$ & $2.9 \pm$ & 2.9 & $4.1 \pm$ & 3.1 & $10.8 \pm$ & 6.1 & $0.3 \pm$ & 0.3 & $0.4 \pm$ & 0.3 & $1.1 \pm$ & 0.6 \\
\hline 1,2,3,6,7,8-HxCDD & $29.7 \pm$ & 24.7 & $41.1 \pm$ & 24.9 & $101 \pm$ & 52.7 & $3.0 \pm$ & 2.5 & $4.1 \pm$ & 2.5 & $10.1 \pm$ & 5.3 \\
\hline 1,2,3,7,8,9-HxCDD & $4.2 \pm$ & 3.2 & $6.1 \pm$ & 4.8 & $12.7 \pm$ & 6.3 & $0.4 \pm$ & 0.3 & $0.6 \pm$ & 0.5 & $1.3 \pm$ & 0.6 \\
\hline 1,2,3,4,6,7,8-HpCDD & $20.0 \pm$ & 47.4 & $43.0 \pm$ & 112 & $144 \pm$ & 170 & $0.2 \pm$ & 0.5 & $0.4 \pm$ & 1.1 & $1.4 \pm$ & 1.7 \\
\hline OCDD & $305 \pm$ & 596 & $548 \pm$ & 615 & $2650 \pm$ & 3860 & $0.0 \pm$ & 0.1 & $0.1 \pm$ & 0.1 & $0.3 \pm$ & 0.4 \\
\hline $2,3,7,8-\mathrm{TCDF}$ & $1.1 \pm$ & 1.2 & $0.9 \pm$ & 1.0 & $2.4 \pm$ & 1.8 & $0.1 \pm$ & 0.1 & $0.1 \pm$ & 0.1 & $0.2 \pm$ & 0.2 \\
\hline $1,2,3,7,8-\mathrm{PeCDF}$ & $0.6 \pm$ & 0.6 & $0.9 \pm$ & 0.7 & $3.0 \pm$ & 2.3 & $0.0 \pm$ & 0.0 & $0.0 \pm$ & 0.0 & $0.2 \pm$ & 0.1 \\
\hline 2,3,4,7,8-PeCDF & $19.7 \pm$ & 16.4 & $17.7 \pm$ & 13.0 & $61.3 \pm$ & 40.1 & $9.9 \pm$ & 8.2 & $8.8 \pm$ & 6.5 & $30.6 \pm$ & 20.1 \\
\hline $1,2,3,4,7,8-\mathrm{HxCDF}$ & $5.6 \pm$ & 4.2 & $8.4 \pm$ & 6.7 & $32.2 \pm$ & 19.3 & $0.6 \pm$ & 0.4 & $0.8 \pm$ & 0.7 & $3.2 \pm$ & 1.9 \\
\hline $1,2,3,6,7,8-\mathrm{HxCDF}$ & $6.4 \pm$ & 6.4 & $10.5 \pm$ & 9.3 & $53.9 \pm$ & 38.2 & $0.6 \pm$ & 0.6 & $1.1 \pm$ & 0.9 & $5.4 \pm$ & 3.8 \\
\hline 2,3,4,6,7,8-HxCDF & $2.8 \pm$ & 2.4 & $5.9 \pm$ & 7.0 & $26.8 \pm$ & 19.2 & $0.3 \pm$ & 0.2 & $0.6 \pm$ & 0.7 & $2.7 \pm$ & 1.9 \\
\hline $1,2,3,7,8,9-\mathrm{HxCDF}$ & $0.3 \pm$ & 0.5 & $0.7 \pm$ & 0.8 & $2.7 \pm$ & 2.4 & $0.0 \pm$ & 0.1 & $0.1 \pm$ & 0.1 & $0.3 \pm$ & 0.2 \\
\hline $1,2,3,4,6,7,8-\mathrm{HpCDF}$ & $2.2 \pm$ & 3.1 & $5.3 \pm$ & 6.2 & $53.0 \pm$ & 61.6 & NI & & $0.1 \pm$ & 0.1 & $0.5 \pm$ & 0.6 \\
\hline $1,2,3,4,7,8,9-\mathrm{HpCDF}$ & $0.2 \pm$ & 0.6 & $0.7 \pm$ & 1.1 & $8.0 \pm$ & 6.6 & NI & & ND & & $0.1 \pm$ & 0.1 \\
\hline $\mathrm{OCDF}$ & $0.3 \pm$ & 0.6 & $0.7 \pm$ & 1.1 & $8.2 \pm$ & 10.7 & NI & & ND & & ND & \\
\hline 3,3',4,4'-TCB & $34.2 \pm$ & 78.4 & $62.4 \pm$ & 62.4 & 210 & 369 & NL & & ND & & ND & \\
\hline 3,3'4,4',5-РeCB & $125 \pm$ & 105 & $122 \pm$ & 71.3 & 353 & 180 & $12.5 \pm$ & 10.5 & $12.2 \pm$ & 7.1 & $35.3 \pm$ & 18.0 \\
\hline 3,3'4,4'5,5'-НxCB & $127 \pm$ & 244 & $121 \pm$ & 87.5 & $274 \pm$ & 162 & $1.3 \pm$ & 2.4 & $1.2 \pm$ & 0.9 & $2.7 \pm$ & 1.6 \\
\hline PCDDs & $376 \pm$ & 649 & $655 \pm$ & 724 & 2950 & 4020 & $18.0 \pm$ & 13.8 & $18.1 \pm$ & 10.9 & $46.6 \pm$ & 25.7 \\
\hline PCDFs & $39.1 \pm$ & 30.6 & $51.6 \pm$ & 39.2 & 251 & 129 & $11.5 \pm$ & 9.3 & $11.6 \pm$ & 8.4 & $43.2 \pm$ & 24.5 \\
\hline Co-PCBs & $286 \pm$ & 309 & $306 \pm$ & 181 & 837 & 491 & $13.7 \pm$ & 11.1 & $13.5 \pm$ & 7.6 & $38.0 \pm$ & 19.0 \\
\hline Total & $701 \pm$ & 773 & 1010 & 826 & 4040 & 4110 & $43.2 \pm$ & 30.9 & $43.1 \pm$ & 24.2 & $128 \pm$ & 57.4 \\
\hline
\end{tabular}


Dioxins in bile of humans.

demonstrated in Fig. 1. The correlation coefficient $r$ was 0.89 , and the regression equation was $\mathrm{y}=1.14 \mathrm{x}-$ 6.02, where y indicates total-TEQ per $\mathrm{g}$ lipid of bile, and $\mathrm{x}$ is total-TEQ per $\mathrm{g}$ lipid of the blood. We also examined the relationship between blood total-TEQ and liver total-TEQ. As demonstrated in Fig.1, this also showed good correlation, with a correlation coefficient of 0.73 , and the relationship can be expressed as $y=$ $1.74 \mathrm{x}+52.9$, where $\mathrm{y}$ is total-TEQ in terms of per $\mathrm{g}$ lipid of liver and $\mathrm{x}$ is total-TEQ per $\mathrm{g}$ lipid of blood.

\section{Accumulation rate of dioxins in bile, blood and liver}

Although the number of samples was not large, the ages of the subjects were distributed relatively well between 21 and 85 . Therefore, we examined by age accumulation rates of dioxins in the bile, blood and liver, for total-TEQ and each of five congeners mostly contributing to the total-TEQ. Regression analysis between total-TEQ and age revealed that there is rela- tively good correlation in these organs, with correlation coefficients of $0.52(\mathrm{p}<0.01), 0.47(\mathrm{p}<0.05)$ and 0.54 $(\mathrm{p}<0.01)$ in bile, blood and liver, respectively (Table 5). Further it was estimated that dioxins appeared in bile after about age 20, in contrast to the blood in which dioxins appeared from age zero (Fig. 2.).

In bile, all of the major five congeners also showed a positive correlation between age and their levels, although there are some exceptional cases in blood and liver (Table 5). Regression lines indicated that all of the major five congeners appeared after about age 20 in bile, although appearance patterns are different by congener in blood and liver (Fig. 2).

\section{Relationship between dioxin levels and disease at death}

Eight of 12 cases of women and 10 of 15 cases of men were associated with malignant changes: three lung cancers, three malignant lymphomas, two urothe-

Table 3. Comparisons of PCDD / PCDF / Co-PCB levels among bile, blood and liver.

\begin{tabular}{|c|c|c|c|}
\hline & Bile / Blood & Liver / Blood & Liver / Bile \\
\hline & Mean \pm SD & Mean \pm SD & Mean \pm SD \\
\hline \multicolumn{4}{|l|}{$\mathrm{pg} / \mathrm{g}$ lipid basis } \\
\hline $2,3,7,8-\mathrm{TCDD}$ & $1.5 \pm 1.5$ & $3.3 \pm 2.7$ & $3.7 \pm$ \\
\hline $1,2,3,7,8-\mathrm{PeCDD}$ & $1.1 \pm 0.6$ & $3.2 \pm$ & $3.1 \pm$ \\
\hline $1,2,3,4,7,8-\mathrm{HxCDD}$ & $0.7 \pm 0.4$ & $3.7 \pm$ & $7.0 \pm$ \\
\hline $1,2,3,6,7,8-\mathrm{HxCDD}$ & $0.7 \pm 0.5$ & $3.1 \pm$ & $6.5 \pm$ \\
\hline $1,2,3,7,8,9-\mathrm{HxCDD}$ & $0.8 \pm 0.7$ & $3.1 \pm 2.6$ & $4.4 \pm \quad 4.6$ \\
\hline $1,2,3,4,6,7,8-\mathrm{HpCDD}$ & $0.7 \pm 0.6$ & $9.3 \pm 12.1$ & $24.8 \pm 41.0$ \\
\hline OCDD & $0.8 \pm 1.1$ & $7.2 \pm 6.6$ & $20.4 \pm 33.2$ \\
\hline 2,3,7,8-TCDF & $1.5 \pm 1.8$ & $2.1 \pm$ & $2.6 \pm 2.3$ \\
\hline $1,2,3,7,8-\mathrm{PeCDF}$ & $0.8 \pm 1.2$ & $3.9 \pm$ & $6.4 \pm 10.5$ \\
\hline 2,3,4,7,8-PeCDF & $1.1 \pm 0.6$ & $4.2 \pm$ & $4.9 \pm 4.8$ \\
\hline $1,2,3,4,7,8-\mathrm{HxCDF}$ & $0.8 \pm 0.5$ & $5.4 \pm$ & $7.9 \pm 5.1$ \\
\hline $1,2,3,6,7,8-\mathrm{HxCDF}$ & $0.7 \pm 0.5$ & $7.6 \pm$ & $15.2 \pm 16.2$ \\
\hline $2,3,4,6,7,8-\mathrm{HxCDF}$ & $0.7 \pm 0.6$ & $\begin{array}{l}1.0 \pm \\
7.3 \pm\end{array}$ & $16.3 \pm 16.9$ \\
\hline $1,2,3,7,8,9-\mathrm{HxCDF}$ & $0.7 \pm 1.7$ & $4.0 \pm \quad 5.0$ & $5.6 \pm \quad 8.7$ \\
\hline $1,2,3,4,6,7,8-\mathrm{HpCDF}$ & $0.5 \pm 0.6$ & $21.6 \pm 34.3$ & $39.6 \pm 58.6$ \\
\hline $1,2,3,4,7,8,9-\mathrm{HpCDF}$ & $0.5 \pm 1.1$ & $8.5 \pm \quad 8.8$ & $12.3 \pm 13.3$ \\
\hline OCDF & $0.1 \pm 0.2$ & $6.1 \pm 10.7$ & $18.9 \pm 33.9$ \\
\hline 3,3',4,4'-TCB & $0.8 \pm 1.2$ & $8.1 \pm 13.7$ & $13.6 \pm 27.0$ \\
\hline $3,3^{\prime} 4,4^{\prime}, 5-\mathrm{PeCB}$ & $1.1 \pm 0.7$ & $3.8 \pm \quad 2.7$ & $4.8 \pm \quad 4.0$ \\
\hline $3,3^{\prime} 4,4^{\prime} 5,5^{\prime}-\mathrm{HxCB}$ & $0.9 \pm 0.9$ & $2.9 \pm \quad 1.8$ & $6.8 \pm$ \\
\hline \multicolumn{4}{|c|}{ Congener group-pg TEQ/g lipid basis } \\
\hline PCDDs & $1.0 \pm 2.1$ & $1.9 \pm$ & $2.7 \pm$ \\
\hline PCDFs & $0.9 \pm 1.4$ & $3.5 \pm$ & $3.7 \pm$ \\
\hline Co-PCBs & $1.0 \pm 1.5$ & $2.0 \pm \quad 1.4$ & $2.7 \pm$ \\
\hline Total & $1.1 \pm 2.8$ & $2.6 \pm 3.2$ & $3.2 \pm$ \\
\hline
\end{tabular}




\section{K. KITAMURA et al.}

lial cancers, two pancreatic cancers, two hepatomas, two acute myelocytic leukemias and one cancer in the spinal cord, ovary, brain, stomach, colon, bladder and prostate. Three cases in men were associated with double cancers. Total-TEQ ranged from 17.1 to $287.3 \mathrm{pg}$ TEQ per g lipid in the liver. However, there was no correlation between cancer diagnosis and the level of dioxins.

\section{DISCUSSION}

This study first demonstrated that the dioxin level in bile is almost the same as the level in blood in terms of TEQ per $g$ lipid. The same level as in blood was observed not only as the mean, but also in the 27 cases, with a correlation coefficient of 0.89 . The bile and blood levels were one-third of that in the liver in terms

Table 4. Daily secretion of dioxins into bile.

\begin{tabular}{ll}
\hline & pg TEQ/day \\
\hline PCDDs & $22.8 \pm 23.2$ \\
PCDFs & $14.3 \pm 14.3$ \\
Co-PCB & $16.7 \pm 17.7$ \\
Total & $53.9 \pm 52.5$ \\
\hline
\end{tabular}

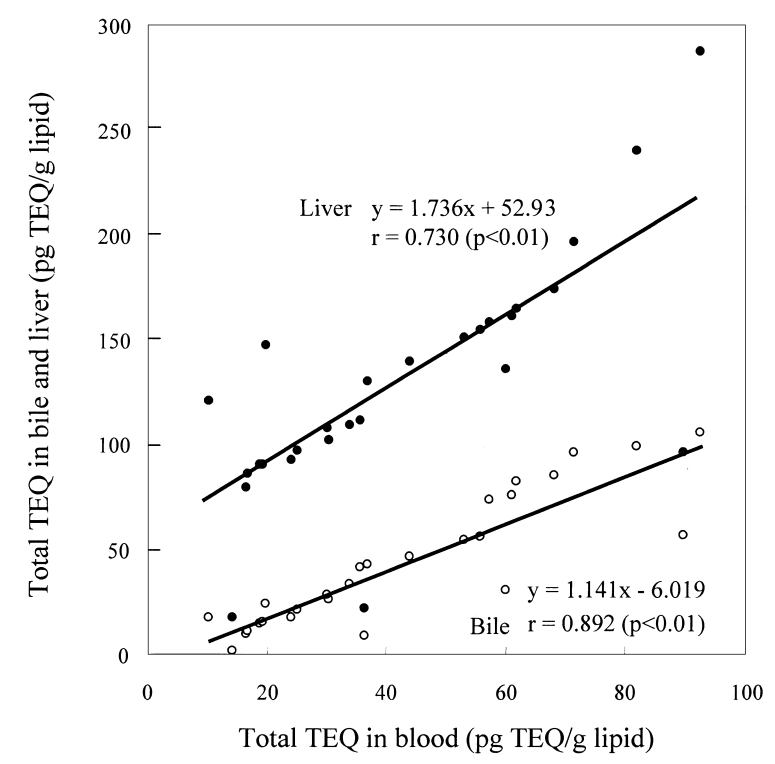

Fig. 1. Dioxin TEQ: Relationship among blood, bile and liver. Open circles indicate bile and blood TEQ, and closed circles liver and blood TEQ of each autopsy sample. of TEQ per g lipid. Iida et al. (1999) also reported a similar trend in the ratio between blood and liver, although the ratio of liver to blood was 4.6 in their cases. It is noteworthy that the dioxin burden in liver is 38 times higher than that in blood in terms of per organ weight. These dioxins in liver would be distributed to various organs, including bile and blood. However, there was a tendency that congeners with higher numbers of chlorine atoms were less efficiently distributed to bile when compared with blood, and OCDF was hardly distributed to bile.

It has been reported that $2,3,7,8$-TCDD is not detected in the bile of guinea pigs after intra-peritoneal administration, and it was suggested that the fecal excretion of 2,3,7,8-TCDD in this animal resulted from direct intestinal elimination (Olson, 1986). However, in the present study it was demonstrated that $2,3,7,8$ TCDD is present in human bile at levels similar to blood, in terms of per g lipid.

Regression analysis of the 27 cases revealed that bile dioxin levels (total-TEQ) can be deduced based on blood total-TEQ levels with an equation of $\mathrm{y}=1.14 \mathrm{x}-$ 6.02 , where $\mathrm{x}=$ total-TEQ value of blood (on $\mathrm{g}$ lipid basis). Further, we can deduce liver dioxin levels, by the equation of $y=1.74 x+52.9$ with a correlation coefficient of 0.73 , with $\mathrm{x}=$ total-TEQ value of blood. Iida et al. (1999) also demonstrated the presence of a good correlation between the blood and liver in levels of several congeners of PCDDs, PCDFs and Co-PCBs, although they did not conduct studies on total-TEQ.

We recently clarified that about $50 \%$ of the totalTEQ of dioxins ingested is excreted, $22 \%$ in feces and $29 \%$ in sebum (Kitamura et al., 2001). The fate of the remaining $50 \%$ is not known. One possibility is accumulation in the body. Therefore, we examined the effect of age on dioxin levels, and it was revealed that total-TEQ and the major five congeners mostly contributing to the total-TEQ increased with age in bile, blood and liver (Fig.2). The accumulation rate of dioxins was estimated to be $0.99,0.70$ and $1.91 \mathrm{pg}$ totalTEQ/ g lipid / year in bile, blood and liver, respectively (Table 5). However, it is necessary to pay attention to the fact that these rates might be largely affected by the assize of historical exposure. The accumulation rate was about 2 times higher in the liver than in the bile or blood (Table 5). It is noteworthy that dioxins are estimated to be present at age naught in the blood and liver; however, they showed a tendency to appear in bile after about age 20. Since the number of samples of about age 20 was small, and furthermore, we did not examine samples from less than age 20 , it is necessary 
Dioxins in bile of humans.

a)
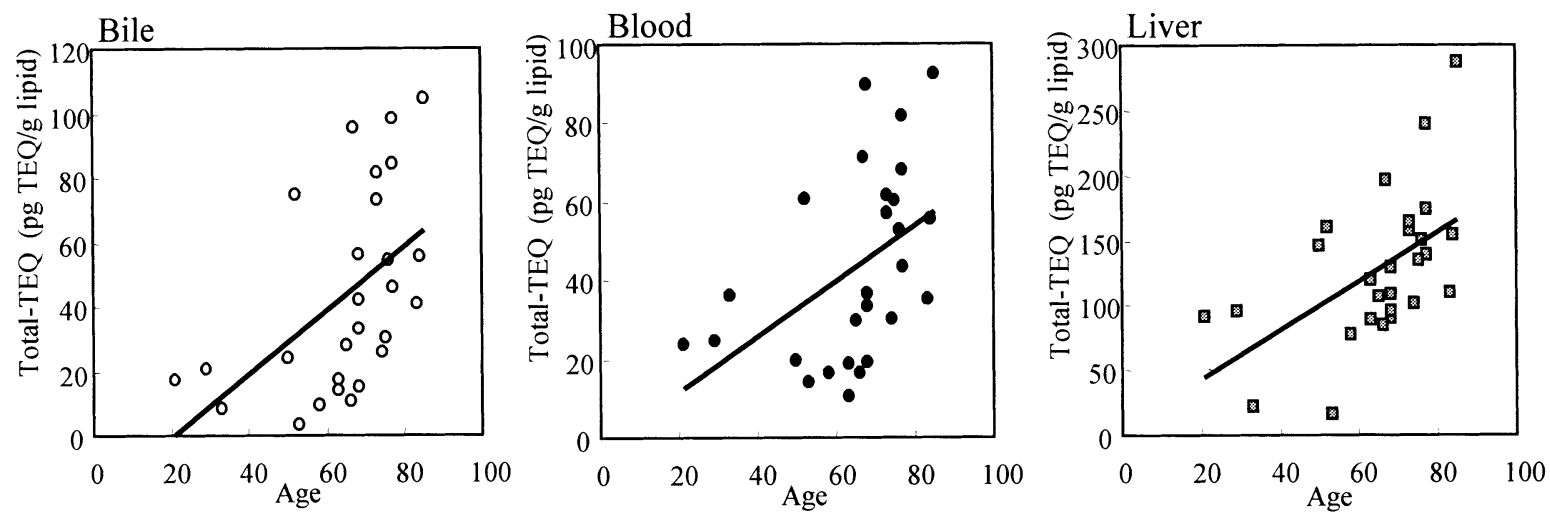

b)
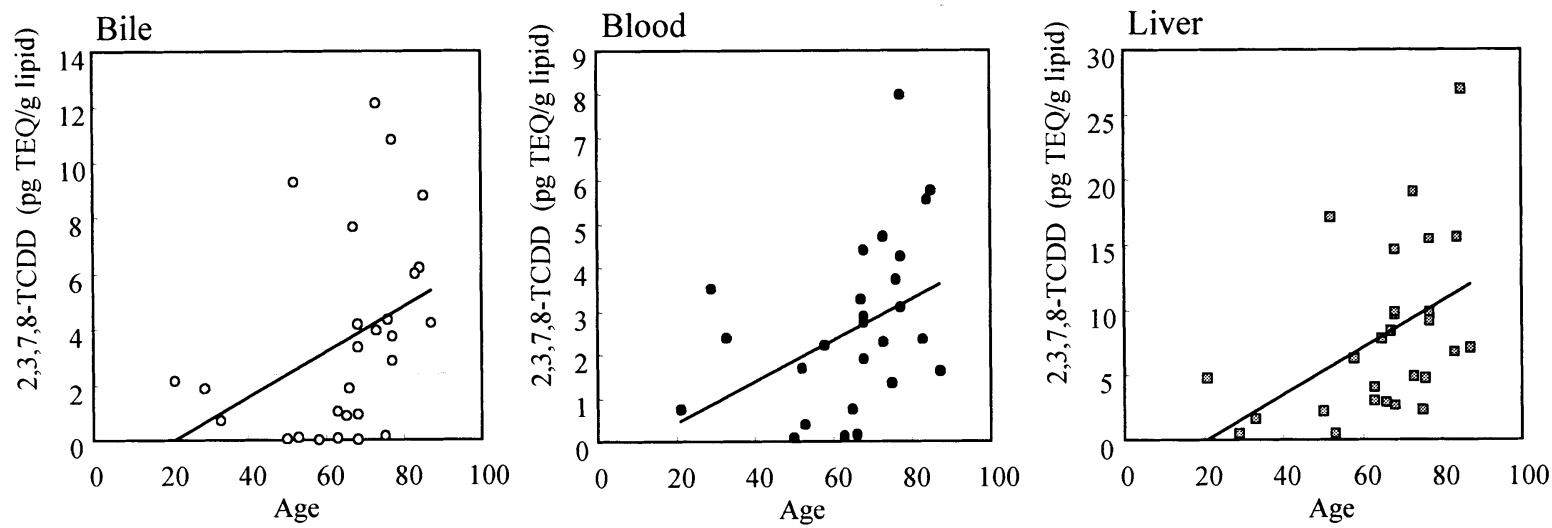

c)
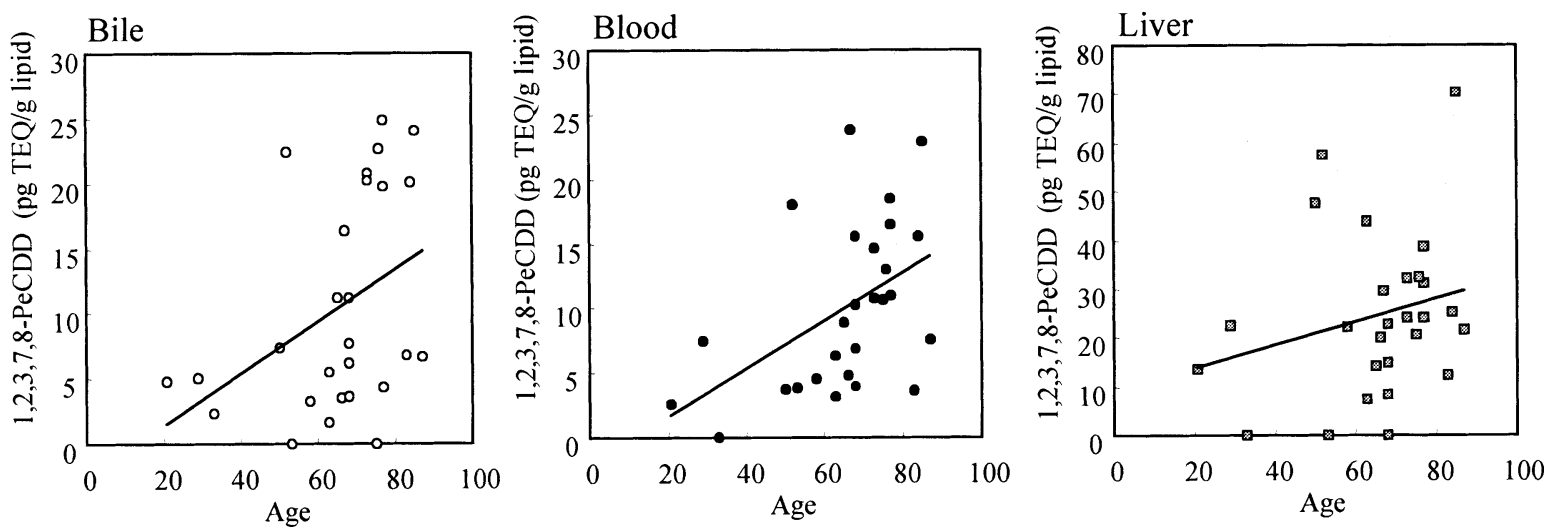

Fig. 2-1. Relationships between age and total-TEQ, and age and the major five dioxin congeners. a), total-TEQ in bile, blood and liver: b), 2,3,7,8-TCDD in bile, blood and liver: c), 1,2,3,7,8-PeCDD in bile, blood and liver. 
d)
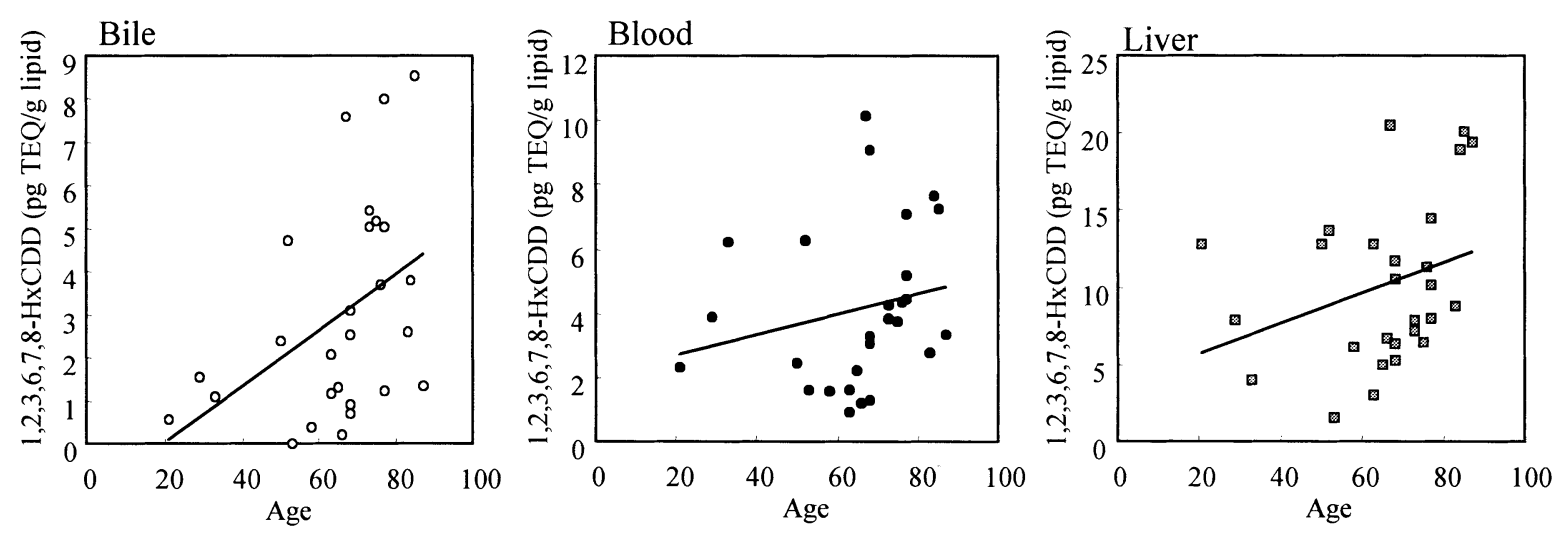

e)
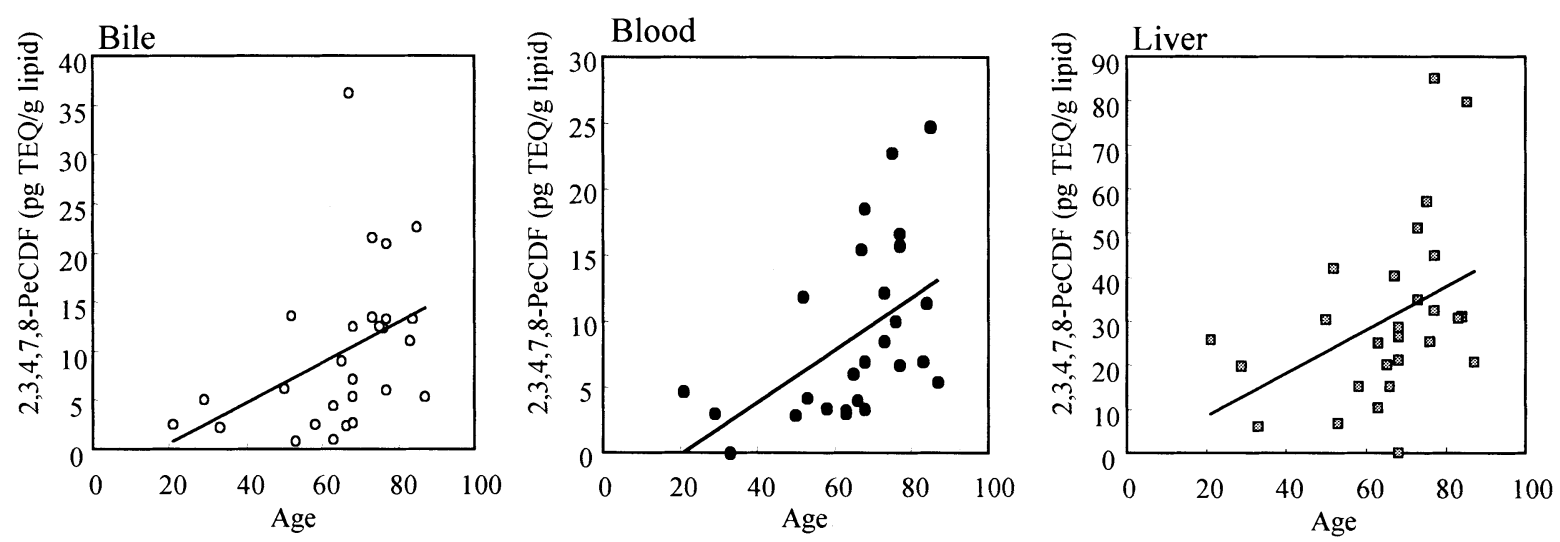

f)
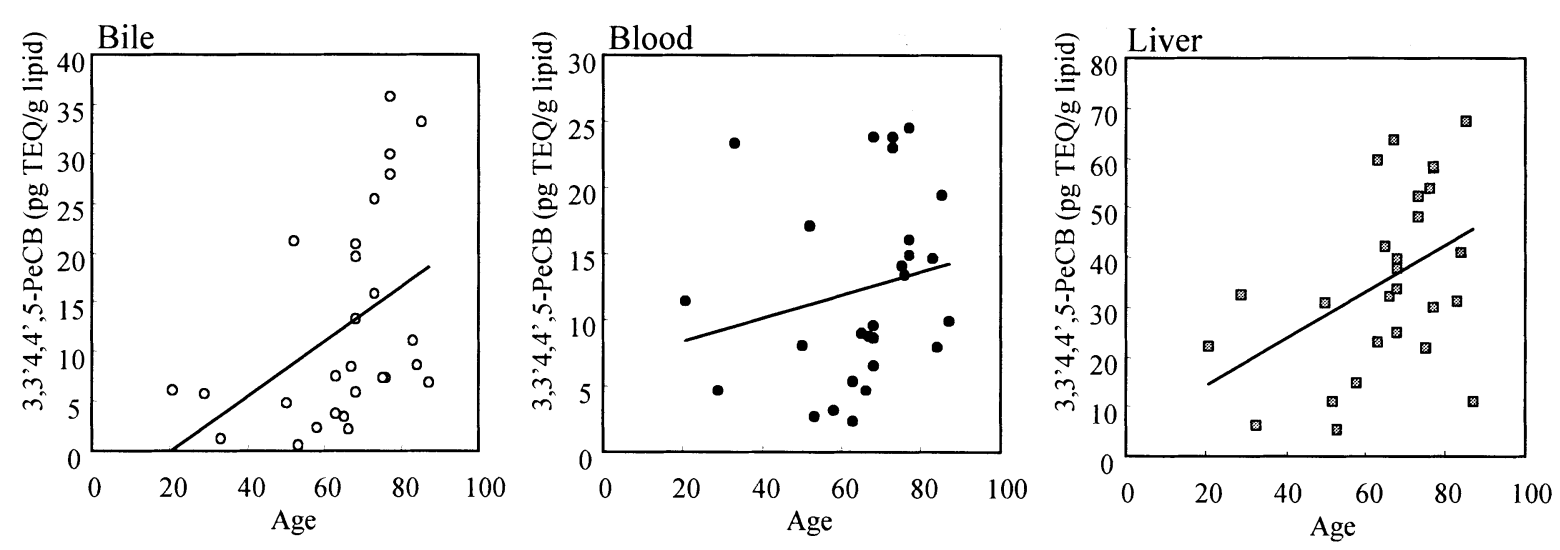

Fig. 2-2. Relationships between age and total-TEQ, and age and the major five dioxin congeners. d), 1,2,3,6,7,8-HxCDD in bile, blood and liver: e), 2,3,4,7,8-PeCDF in bile, blood and liver: f), 3,3'4,4',5-PeCB in bile, blood and liver. 
Dioxins in bile of humans.

to confirm this point. However, by assuming that this is the case, two possible mechanisms for the delayed appearance in bile can be considered: secretion to bile might occur after accumulation of dioxins in liver has reached certain levels, or processes involved in the metabolism of dioxins might change after age about 20.

It was calculated that daily secretion of dioxins from bile is 54 pg TEQ, which corresponds to 30 40\% of the total ingestion of dioxins of the Japanese, based on the data from a study by the Ministry of Health and Welfare (Toyoda et al., 1999). Since our previous study (Kitamura et al., 2001) indicated that $80 \%$ of dioxins to which intestines are exposed might be absorbed, prevention of absorption from intestines would be one important approach to reducing the body burden of dioxins. Aozasa et al. (2000) reported efficient elimination of dioxins by feeding chitosan-bound chlorophilline to rats. This line of study may be useful to reduce the body burden of dioxins in humans.

\section{ACKNOWLEDGMENT}

We thank Dr. Takao Iida for his helpful discussion.

We thank Professor Kunie Yoshikawa for his support for preparation of this manuscript. This study was supported by Grants-in-Aid for the Fundamental Research fund for the Environment, Grants-in-Aid for Research on Environmental Health (H10-Seikatsu-007, H11-Seikatsu-026) from the Ministry of Health and Welfare, a research grant from the Ministry of Education, Sports, Culture and Science (13027283), a grant from the Foundation for Promotion of Cancer Research Japan, National Grant-in-Aid for the Establishment of High-Tech Research Center in Private University, Keio Gijyuku Academic Development Funds, a special grant-in-aid for innovative and collaborative research projects at Keio University, and a grant from Yaizu Suisan Co. Ltd., Yaizu Shizuoka , Japan

\section{REFERENCES}

Aozasa, O., Tesumi, T., Ohta, S., Nakao, T. and Miyata,

Table 5. Relation between age and TEQ.

\begin{tabular}{|c|c|c|c|c|c|}
\hline \multirow[b]{2}{*}{ Dioxin congeners } & \multirow[b]{2}{*}{ Organ } & \multicolumn{2}{|c|}{ Regression equation* } & \multirow{2}{*}{$\begin{array}{l}\text { Correlation } \\
\text { coefficient }\end{array}$} & \multirow[b]{2}{*}{$\mathrm{p}$ value } \\
\hline & & $\mathrm{a}$ & $\mathrm{b}$ & & \\
\hline \multirow[t]{3}{*}{20 Congeners (total) } & Bile & 0.991 & -20.9 & 0.520 & $<0.01$ \\
\hline & Blood & 0.704 & -2.37 & 0.473 & $<0.05$ \\
\hline & Liver & 1.91 & 4.36 & 0.539 & $<0.01$ \\
\hline \multirow[t]{3}{*}{ 2,3,7,8-TCDD } & Bile & 0.082 & -1.74 & 0.386 & $<0.05$ \\
\hline & Blood & 0.048 & -0.567 & 0.402 & $<0.05$ \\
\hline & Liver & 0.182 & -3.82 & 0.467 & $<0.05$ \\
\hline \multirow[t]{3}{*}{ 1,2,3,7,8-PeCDD } & Bile & 0.203 & -2.76 & 0.407 & $<0.05$ \\
\hline & Blood & 0.185 & -2.09 & 0.479 & $<0.05$ \\
\hline & Liver & 0.238 & 8.86 & 0.236 & $>0.05$ \\
\hline \multirow[t]{3}{*}{ 1,2,3,6,7,8-HxCDD } & Bile & 0.065 & -1.26 & 0.438 & $<0.05$ \\
\hline & Blood & 0.031 & 2.07 & 0.210 & $>0.05$ \\
\hline & Liver & 0.099 & 3.70 & 0.313 & $>0.05$ \\
\hline \multirow[t]{3}{*}{ 2,3,4,7,8-PeCDF } & Bile & 0.206 & -3.55 & 0.421 & $<0.05$ \\
\hline & Blood & 0.199 & -4.10 & 0.511 & $<0.01$ \\
\hline & Liver & 0.494 & -1.53 & 0.411 & $<0.05$ \\
\hline \multirow[t]{3}{*}{ 3,3'4,4',5-PeCB } & Bile & 0.280 & -5.73 & 0.446 & $<0.05$ \\
\hline & Blood & 0.089 & 6.46 & 0.208 & $>0.05$ \\
\hline & Liver & 0.474 & 4.37 & 0.440 & $<0.05$ \\
\hline
\end{tabular}

* Regression equation, $\mathrm{y}=\mathrm{ax}+\mathrm{b}$ (pg TEQ /g lipid), $\mathrm{x}=$ age (year) 


\section{K. KITAMURA et al.}

H. (2000): Promoting fecal excretion of accumulated dioxins by porphyrin-dietary fiber. Organohalogen Compounds, 48, 327-330.

Beck, H., Dro $\beta$, A., Kleemann, W.J. and Mathar, W. (1990): PCDD and PCDF concentrations in different organs from infants. Chemosphere, 20, 903-910.

EPA, USA, Office of Water, Engineering and Analysis Division (1994): Method 1613: Tetra- through octa-chlorinated dioxins and furans by isotope dilution HRGC/HRMS, EPA 821·B-94-005, Revision B.

Iida T., Hirakawa, H., Matsueda, T., Nagauama, J. and Nagata, T. (1999): Polychlorinated dibenzo-pdioxins and related compounds: Correlations of levels in human tissues and in blood. Chemosphere, 38, 2767-2774.

International Agency for Research on Cancer (1997): Polychlorinated dibenzo-para-dioxins and polychlorinated dibenzofurans. IARC Monographs on the Evaluation of Carcinogenic Risks to Humans, 69, 1-636.

Kitamura, K., Nagahashi, M., Sunaga, M., Watanabe, S. and Nagao, M. (2001): Balance of intake and excretion of 20 congeners of polychlorinated dibenzo- $p$-dioxin, polychlorinated dibenzofuran and coplanar polychlorinated biphenyl in healthy Japanese men. J. Health Sci., 47, 145-154.

Masuzaki, Y., Matsumura, T., Hattori, T., Kimura, S., Noda, H., Hashimoto, S. and Morita, M. (1999): Sensitive determination methods of dioxins and related compounds in human blood. Organohalogen Compounds, 40, 227-230.

Michalek, J.E., Pirkle, J.L., Caudill, S.P., Tripathi, R., Patterson, D.G. Jr. and Needham, L.L. (1996): Pharmacokinetics of TCDD in veterans of Operation Ranch Hand: 10-Year follow-up. J. Toxicol. Environ. Health, 47, 209-220.

Miyata, H., Kuriyama, S., Nakao, T., Aozasa, O. and Ohta, S. (1998): Contamination levels of PCDDs,
PCDFs and non-orthocoplanar PCBs in blood samples collected from residents in high cancercausing area close to batch-type municipal solid waste incinerator in Japan. Organohalogen Compounds, 38, 143-146.

Miyata, H., Takayama K., Ogaki J., Miura, M., Kashimoto, T. and Yamada, T. (1989): Coplanar PCBs and PCDFs in patients with Yusho Disease and in the Yusho oil. Chemosphere, 18, 407-416.

Olson, J.R. (1986): Metabolism and disposition of 2,3,7,8-tetrachlorodibenzo- $p$-dioxin in guinea pigs. Toxicol. Appl. Pharmacol., 83, 263-273.

Ott, M.G. and Zober, A. (1996): Cause of specific mortality and cancer incidence among employees exposed to 2,3,7,8-TCDD after a 1953 reactor accident. Occup. Environ. Med., 53, 606-612.

Rohde, S., Moser, G.A., Papke, O. and McLachlan, M.S. (1999): Clearance of PCDD/Fs via the gastrointestinal tract in occupationally exposed persons. Chemosphere, 38, 3397-3410.

Safe, A. (1991): Polychlorinated dibenzo-p-dioxins and related compounds: Sources, environmental distribution and risk assessment. Environ. Carcinog. Ecotoxicol. Rev., C9, 261-302.

Schecter, A., Cramer, P., Boggess, K., Stanley, J., Olson, J.R. and Kessler, H. (1996): Dioxin intake from US food: Results from a new nationwide food survey. Organohalogen Compounds, 28, 320-324.

SPSS version 10.0J (1999): SPSSINC, Chicago, IL.

Toyoda, M., Uchibe, H., Yanagi, T., Kono, Y., Hori, T. and Iida, T. (1999): Dietary daily intake of PCDDs, PCDFs and Coplanar PCBs by total diet study in Japan. Shokuhin Eisei Gakkaishi, 40, 98110.

US Department of Health and Human Services. (1998): Toxicological profile for chlorinated dibenzodioxins. Agency for Toxic Substances and Disease Registry, Atlanta. 